\title{
Análise da Satisfação dos Funcionários com as Políticas e Práticas de Recursos Humanos Utilizadas pelas Agências de Viagem e Turismo da Cidade do Recife-PE, Brasil
}

\author{
Analysis of Employee Satisfaction with Human Resource Practices \\ and Policies Used by Travel Agencies in Recife-PE, Brazil
}

\section{Christiane de Melo Rêgo Souto ${ }^{1}$ Lúcia Maria Barbosa de Oliveira ${ }^{2}$}

\begin{abstract}
RESUMO: O principal objetivo do estudo foi o de investigar a satisfação de funcionários com as políticas e práticas de $\mathrm{RH}$ utilizadas pelas agências de viagens de Recife. A pesquisa realizada caracteriza-se como exploratório-descritiva. Foram pesquisadas oito agências, de uma amostra intencional não probabilística, perfazendo um total de 91 funcionários de linha de frente (emissores). Os dados foram coletados por meio de questionário e na análise foram utilizadas estatística descritiva e análise fatorial. Os resultados do estu-

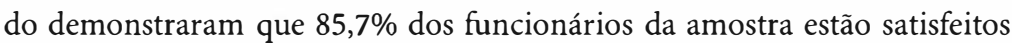
com o seu trabalho na agência de viagem e que os itens remuneração e treinamento explicam $48,8 \%$ da escala de satisfação com práticas e políticas de recursos humanos. A recompensa aparece assim como um meio poderoso de satisfação de funcionários.
\end{abstract}

1. Graduada em Turismo pela FIR-PE e mestre em Administração de Empresas pelo PROPAD/UFPE. Coordenadora do Curso Seqüencial de Gestão de Marketing e do Curso de Logística da FBV; professora da FBV na área de gestão de marketing. Contato: FBV - Av. Conde da Boa Vista, 1410 - 50060-002 - Recife-PE; e-mail: christianesouto@fbv.br.

2. Ph.D em Relaçôes Industriais pela London School of Economics - LSE. Coordenadora Geral de Pós-Graduação, Pesquisa e Extensão da FBv; professora titular da FBV da área de gestão de pessoas, onde ensina na graduação e no mestrado. Contato: FBV - Av. Conde da Boa Vista, 1410 - 50060-002 -Recife-PE; e-mail: luciabarbosa@fbv.br. 
PALAVRAS-CHAVE: satisfação; políticas e práticas de RH; agências de viagens.

ABSTRACT: The main purpose of this study was to investigate employee satisfaction with human resource practices and policies used by travel agencies in Recife, Brazil. It is a descriptive-exploratory study. Eight agencies were researched as a non-probabilistic intentional sample with 91 face-to-face contact employees (travel agents). The data were collected by means of questionnaires and descriptive statistical and factorial analyses were applied. The study results demonstrate that $85.7 \%$ of the employees researched are satisfied with their work at the travel agency and that remuneration and training items explain $48.8 \%$ of the satisfaction scale of human resource policies and practices. In this study, therefore, recompense appears as a powerful means for employee satisfaction.

KEYWORDS: satisfaction; human resource practices and policies; travel agencies.

\section{Introdução}

No Brasil e no mundo, nas últimas duas décadas, as empresas turísticas passaram a enfrentar novos desafios, pois a melhoria da eficiência interna deixou de garantir a sua sobrevivência e o seu crescimento. Segundo Beni (1996), em todo o mundo, constata-se a explosão de projetos, a construção de aeroportos, navios, aviões e meios de hospedagem, visando atender a uma demanda global crescente.

Dados da OMT - Organização Mundial do Turismo e do "World Travel \& Tourism Council", para o ano de 2005, confirmaram um movimento físico real de 808 milhões de deslocamentos mundiais, originados pela atividade turística em todo o mundo, correspondendo a um montante de US\$ 4 trilhões de renda, revelando uma significativa participação de aproximadamente $10 \%$ do PIB mundial. Ainda segundo dados da OMT de 2005, o turismo é assim, reconhecidamente, a indústria que mais emprega no mundo, com aproximadamente 200 milhões de empregos, envolvendo muitas profissões e especialidades necessárias para a produção e desenvolvimento econômico do globo.

Particularmente no Brasil, segundo informações da EMBRATUR (2001), a estabilização da economia, no ano de 1994, marcou o início de um novo ciclo de investimentos em modernização e ampliação da oferta turística nacional. Entretanto, de acordo com Andrade (1998), dentre os diversos países do mundo que utilizam o turismo como incremento da sua economia, o Brasil situa-se no bloco intermediário, dos que utilizam, de forma pouco expressiva, suas agências de viagem, como canal condutor da demanda para o turismo interno e emissor, para o turismo internacional.
Diante de um quadro de crescimento no fluxo de turistas e de acirramento da concorrência entre as agências de viagem, a busca incessante pelo melhoramento da prestação de serviços, parece estar se convertendo em um desafio para as empresas que competem nos mercados onde os bens e serviços vendidos são mais e mais parecidos (principalmente no ponto de vista dos consumidores). Desta forma, a alternativa para a busca da competitividade parece estar centrada nos diferenciais, pois segundo Porter (1994), as pessoas e o modo de gerenciá-las estão se tornando, a cada dia, mais importante como estratégia competitiva.

Mesmo identificando esta importância, Swarbrooke (2000) afirma que ainda é possível observar que grande parte do debate sobre o turismo parece ignorar os funcionários, preferindo analisar o turista, a comunidade local como um todo e as empresas de turismo, mesmo sendo os funcionários responsáveis por desempenharem um papel fundamental, em todos os aspectos do oferecimento do produto turístico, seja ele em um hotel, em uma companhia aérea ou em uma agência de viagem e turismo.

Em se tratando de agências de viagem, a qualidade do serviço prestado por estas é o resultado do trabalho dos funcionários de linha de frente, bem mais que apenas o resultado do trabalho de gerentes e supervisores. Nelas, os funcionários fazem parte do produto, portanto, é preciso ter uma equipe que atue bem durante os momentos da verdade de acordo com Kotler et al. (1999). Mas na realidade, mesmo estando em contato direto com o cliente, muitos destes funcionários de agências de viagens não recebem capacitação profissional, como mostra uma pesquisa da EMBRATUR (2003).

Para adaptar as agências de viagens a este mercado competitivo, os empresários precisam realizar algumas mudanças e para isto poderão, por exemplo, utilizar as políticas de recursos humanos adequadas ao contexto atual. Desta forma, deve-se investir nestes profissionais por meio de treinamentos e re-treinamentos e lhes criar programa de incentivos, pois isto refletirá nos resultados de vendas e a atitude no serviço, já que bons programas internos criam a satisfação do empregado (Tomelin, 2001; Beni, 1996; Kotler et al., 1999).

Em suma, dadas as novas condições sociais vigentes e o contexto competitivo em que se encontram as empresas turísticas, é possível predizer que, no futuro, não só se competirá por conquistar e manter os clientes, mas também se competirá por manter os recursos humanos; pois de acordo com Donoso (2000), eles constituirão a verdadeira vantagem competitiva das empresas no mercado.

Desta forma, parece certo afirmar que alavancar as estratégias empresariais por intermédio das pessoas é uma maneira particular de criar valor único para os clientes e recompensar funcionários (Gubman, 1999). 


\section{Gestão e políticas de recursos humanos}

Segundo Ulrich (2000) as mudanças exigidas pela globalização, tecnologia, crescimento lucrativo e demanda do consumidor, chamam a atenção das empresas para a competência da força de trabalho e as capacidades organizacionais, principalmente daquelas que dependem da interação cliente/funcionário, como as agências de viagens.

Os processos de mudança organizacionais, na concepção atual, exigem da empresa definição de novos contornos para as políticas de recursos humanos, voltados para a obtenção de resultados em termos de inovação, qualidade de serviços e produtividade no trabalho (Albuquerque, 1999). Entretanto para Swarbrooke (2000), o atual estilo de administração praticada nas empresas turísticas, não condiz com a necessidade de desenvolvimento dos recursos humanos exigidos pelo mercado global.

O uso eficaz dos recursos humanos e o aproveitamento de suas habilidades são de fundamental importância para as empresas que prestam serviços ao consumidor. Segundo vários autores, como por exemplo, Gianesi e Corrêa (1996); Tschohl (1996) e Gubman (1999), as pessoas podem melhorar a qualidade e a vantagem competitiva da empresa, a partir de diversos fatores como: seleção das pessoas certas, corretas regras de benefícios, treinamento adequado, autonomia etc.

\section{Processo de seleção}

A captação de pessoas, realizada com o conhecimento de necessidades futuras ou excessos presentes de capital humano, como afirmam Limongi-França e Eliete Arellano(2002) garante seu alinhamento com a estratégia da empresa, além de permitir uma melhor utilização dos recursos internos e externos, visto que uma seleção errada pode aumentar a insatisfação destes funcionários com o trabalho (Robbins, 2002).

Assim, Gianesi e Corrêa (1996) ratificam afirmando que a função de seleção é importante na tarefa de prover recursos humanos para os sistemas de operações, já que uma força de trabalho qualificada pode ser absorvida pela empresa por meio da seleção. No entanto, é necessário que haja uma visão estratégica do sistema de operações de serviço determinando quais os objetivos da empresa, complementa este mesmo autor, para que os recursos humanos selecionados possam focalizar seus esforços neste sentido.
O fato é que segundo Bohlander et al. (2003), independentemente do tamanho da empresa, a seleção dos melhores e mais brilhantes funcionários, constitui uma base sólida para a tão buscada excelência.

\section{Processo de treinamento}

Tanto os funcionários recém-contratados, como aqueles que já estão na empresa há um longo tempo, ratifica Las Casas (1997), devem estar sempre se atualizando, a respeito das mudanças contextuais, por meio de treinamento. Neste sentido, Giacomini Filho (1997) reconhece que o treinamento é fundamental, entretanto, a educação é pré-requisito para qualquer êxito no processo de reciclagem e na retenção do que é transmitido ao funcionário. Nas agências de viagens, o treinamento continuado, seja em sistemas de emissão, seja em conhecimentos de novos destinos ou meio de hospedagem, facilitam a venda do produto turístico com maior rapidez e qualidade.

A formação técnica dos agentes de viagens é uma condição necessária, assim como a sua atualização permanente em relação aos produtos comercializados pela agência, conforme complementa Las Casas (1997), que diz que o treinamento do indivíduo corresponde ao melhoramento da sua qualidade e capacidade de desempenho.

Donoso (2000) afirma que uma boa organização que treina seus empregados para fazer o seu trabalho bem-feito, dá para eles o conhecimento da função e dissemina um sentimento do comprometimento com o trabalho.

\section{Avaliação do desempenho}

De acordo com Gubman (1999), as pessoas querem saber como estão se saindo, se estão indo pelo caminho certo, se está valendo a pena o esforço empregado, pois do contrário ficam frustradas, desmotivadas e simplesmente não melhoram. A avaliação de desempenho tem como propósito verificar quanto o profissional se adapta aos objetivos da empresa e às demandas e exigências do trabalho.

Segundo Bohlander et al. (2003), esta é uma das ferramentas mais poderosas que as empresas possuem para se alcançar um aumento significativo na produtividade dos seus funcionários, já que ela facilita no cumprimento das metas estratégicas. Ela é necessária para averiguar a correção das ações organizacionais e identificar as necessidades de revisão e melhoria, complementam Hipólito e Reis (2002). 
Assim é fundamental deixar claro aos funcionários o que se espera deles em relação aos padrões de qualidade em atendimento e desempenho, recompensando os que tiverem uma boa atuação e treinando aqueles que necessitam melhor direcionar sua função, em relação aos objetivos da empresa, em um ciclo contínuo (Gianesi \& Corrêa, 1996).

\section{Sistema de recompensa}

Embora não se possa desprezar o valor da recompensa monetária, os principais fatores motivadores, segundo Gianesi Corrêa (1996), estão ligados à consecução de objetivos no trabalho, ao reconhecimento do desempenho, ao próprio trabalho, à responsabilidade e ao crescimento pessoal. Gubman (1999) afirma que devido a estes fatores, algumas empresas em vez de aumentar o salário, tentam satisfazer outras necessidades dos seus funcionários, como, por exemplo: o benefício de aulas de inglês, creche, qualidade de vida no trabalho, opções de participação acionária e orientação de serviços sociais. Ainda de acordo com este autor, há indícios de que estas práticas são mais eficazes que o aumento de salário para a redução da rotatividade de pessoal, absenteísmo e atrasos, além de ter efeito positivo sobre a produtividade.

Particularmente em agências de viagens, os sistemas de recompensa são feitos através dos FAMTOURS ${ }^{3}$, que servem ao mesmo tempo como premiação, uma pequena viagem totalmente gratuita de férias, e como treinamento para o funcionário contemplado.

As organizações de serviço podem ter melhor desempenho investindo em pessoas, através dos fatores acima relacionados, mas também evitando o estresse e a rotatividade, pois o esgotamento dos funcionários, causado pelo estresse, pode ter efeito devastador sobre o espírito coletivo de uma empresa e sobre a qualidade dos serviços (Albrecht, 1993). Complementando Gubman (1999: 30) afirma que:

"As pessoas querem do trabalho o que sempre quiseram: respeito, confiança, controle sobre o que fazem, a oportunidade de fazerem um bom trabalho, interações agradáveis com os colegas e outras pessoas, tratamento justo, a oportunidade de levar uma vida razoável, orgulho com o que fazem e com as realizações que alcançam e a possibilidade de aprender".

3. Viagens de reconhecimento de destinos ou equipamentos turísticos oferecidos às agências de viagens.

\section{Satisfação do funcionário}

Segundo Bastos (1994), com o grande impacto das novas tecnologias em um contexto de crescente globalização da economia, o ambiente empresarial tem passado por inúmeras mudanças nos últimos anos, despertando interesse pela questão de comprometimento de trabalho e pelo conjunto de transformações por ele desencadeado, e isto não é diferente no segmento turístico. Atualmente uma das preocupações das organizações é buscar pessoas que não simplesmente estejam trabalhando para a obtenção de bons salários ou por benefícios imediatos, mas sim, pela satisfação em trabalhar, pelo significado que o trabalho tem para a sua vida.

Locke (1969) define satisfação no trabalho como o estado emocional que traz prazer e que é resultante da apreciação do trabalho de alguém, como tendo atingido ou facilitado a obtenção dos valores do trabalho. Complementando esta definição, Brown e Peterson (1993), afirmam que a satisfação no trabalho engloba a satisfação com o supervisor, tarefa, pagamento, oportunidades de crescimento, colegas de trabalho e clientes.

Segundo Moller (1999), quando os provedores de serviços sentem-se bem tratados, eles tratam melhor os recebedores dos seus serviços. Assim, compreender a importância de se criar condições para que os funcionários participem efetivamente do seu trabalho, tendo orgulho, se comprometendo com o trabalho e lutando pelo futuro da empresa, tem sido uma estratégia fundamental para se alcançar o sucesso, pois o orgulho do que faz é a maior ferramenta para se manter um funcionário motivado (Las Casas, 1997).

A satisfação do funcionário é fundamental no setor de serviços, pois assegura que os funcionários irão tratar os clientes de forma respeitosa. Segundo Arnett et al. (2002), a regra mais importante no serviço é desenvolver um bom relacionamento com os clientes. Corroborando, Ruschmann (1992) afirma que o componente humano é fundamental para o sucesso dos empreendimentos turísticos e que somente um funcionário satisfeito poderá atender com cordialidade e eficiência.

Em relação a este aspecto, Denton (1990) acredita que, no entanto, muitas empresas provocam a insatisfação de seus funcionários através de um sistema de trabalho inadequado e de tratamento injusto. Freqüentemente os funcionários de linha de frente são malpagos e têm pouca perspectiva de carreira, o que torna o trabalho desinteressante. Para Schneider (1980), o que mais provoca insatisfação no trabalho é a falta de apoio gerencial; da mesma forma, um importante determinador de satisfação dos funcionários é a disponibilidade de suporte em áreas de pessoal, processamento central e equipamentos. 
De acordo com Robbins (2002), quando um funcionário realiza um bom trabalho, ele se sente intrinsecamente bem, além disso, assumindo que as empresas geralmente recompensam o bom desempenho, isto pode significar o reconhecimento verbal, um aumento de remuneração e até a probabilidade de promoção. Essas recompensas, por seu lado, ratificam Arnett et al. (2002), aumentam o nível de satisfação com o trabalho por parte dos funcionários, que cooperam de forma adequada com os seus pares, entregam aos clientes um serviço de qualidade e estão comprometidos com a empresa na qual trabalham.

\section{Metodologia de pesquisa}

A análise bibliográfica existente mostrou a presença de uma lacuna em relação aos estudos realizados sobre práticas e políticas de RH e sua relação com a satisfação dos funcionários com o seu trabalho em agências de viagens. Desta forma, a pesquisa pode ser considerada de caráter exploratório descritivo, considerando o pouco conhecimento acumulado e sistematizado sobre as agências de viagens e a indústria do turismo em si (Vergara, 1998; Gil, 1999).

Os meios de investigação utilizados foram: a pesquisa bibliográfica, em que foi feito um levantamento teórico, nos principais meios acadêmicos, analisando-se, posteriormente, a relação de tais conceitos com informações colhidas a partir de uma intervenção empírica, em linha com Vergara (1998); e a pesquisa de campo por meio de um questionário, que ocorreu durante todo o mês de fevereiro de 2005. Este instrumento utilizou escalas já consolidadas por outros pesquisadores em seus estudos, com o intuito de conseguir as dimensões propostas com o objetivo de estudo.

Em relação às variáveis de políticas e práticas de recursos humanos, foi considerada a escala desenvolvida por Curado et al. (1995) e adaptada por Gueiros e Oliveira (2004) em estudos da indústria hoteleira de Pernambuco. O desenho metodológico foi elaborado a partir do esquema proposto e recomendado por Gil (1999) na operacionalização de pesquisas em marketing.

O número de empregados de uma empresa, segundo Gueiros e Oliveira (2004), pode refletir a necessidade desta em formalizar as suas práticas e políticas de recursos humanos. Assim, buscou-se as grandes agências de viagens da cidade de Recife (em número de funcionários de contato) dentre as 108 agências filiadas pela ABAV-PE - Associação das Agências de Viagens de Pernambuco. A amostra foi escolhida por acessibilidade, ou seja, foram analisados todos os funcionários que trabalham na emissão das 8 (oito) agências que atenderam ao chamado de participarem do estudo.
Os 91 (noventa e um) funcionários da amostra foram questionados diretamente em seus locais de trabalho, no horário de almoço, onde a pesquisadora entregou o formulário a ser preenchido. Este questionário estava estruturado em três blocos: a) bloco 1 analisava a satisfação com as políticas e práticas de recursos humanos ( 22 perguntas fechadas em escala Likert de 7 pontos); b) bloco 2 buscava informações demográficas dos funcionários; e c) bloco 3 identificava se existia ou não a prática de pesquisa de satisfação interna por parte das agências de viagem e turismo (pergunta fechada do tipo sim ou não).

Para a análise dos dados quantitativos deste estudo, foram utilizadas técnicas: estatística descritiva; e análise fatorial, e aplicado o programa SPSS 11.0 (Statistical Package for Social Science).

\section{Resultados}

\section{Estatística descritiva}

O perfil demográfico dos funcionários estudado nesta pesquisa é o seguinte:

- $86,8 \%$ dos respondentes são do gênero feminino;

- $40 \%$ dos respondentes encontram-se na faixa etária de 26 a 35 anos;

- $67 \%$ dos respondentes possuem terceiro grau completo e $6,6 \%$ possuem pós-graduação;

- $68,1 \%$ dos respondentes são solteiros; e

- 35,5\% dos respondentes têm renda familiar acima de 12 salários míni$\operatorname{mos}^{4}$.

Foi identificado que a maior parte das agências de viagens da amostra utiliza pesquisas de satisfação junto aos seus funcionários, visto que $57,2 \%$ dos respondentes afirmaram terem sido questionados quanto a sua satisfação. Este fato pode indicar o alto grau de satisfação geral dos funcionários em relação ao seu trabalho nas agências de viagem $(85,7 \%)$.

\section{Análise da escala de satisfação com práticas e políticas de RH}

A análise desta escala está relacionada à mensuração da satisfação dos funcionários de linha de frente (emissores), com as políticas e práticas de recursos

4. O salário mínimo na época da realização da pesquisa era de $\mathrm{R} \$ 260,00$. 
humanos, utilizadas pelas agências de viagens nas quais eles trabalham. A análise de confiabilidade da escala que mede o grau de satisfação dos funcionários com estas políticas e práticas, adaptada por Gueiros e Oliveira (2002; 2004), apresentou um coeficiente alfa de 0,91 , o que indica índices considerados satisfatórios.

Os dados apresentados na Tabela 1 levam a crer que os funcionários estão, de uma forma geral, satisfeitos com as políticas e práticas utilizadas pelas agências de viagem na qual trabalham, pois a média geral encontrada foi de 5,08. Ressalta-se o item 17, relacionamento com os colegas de trabalho, obteve a maior média 6,47, seguido do item 1 , forma como foi chamado para trabalhar na empresa, que obteve média de 6,34 e o maior grau de concordância $(94,5 \%)$.

Freqüências acima de $90 \%$ de concordância também foram encontradas nos itens relacionados a equipamentos disponíveis para a execução do trabalho e contribuição do trabalho exercido para o sucesso da empresa, com 93,4\% de concordância.

Tabela 1. Satisfação com as práticas e políticas de RH

\begin{tabular}{|c|c|c|c|}
\hline \multirow[t]{2}{*}{ Itens } & \multicolumn{3}{|c|}{$\%$ Concorda } \\
\hline & $\begin{array}{l}\text { Média } \\
\text { (a) }\end{array}$ & (b) & $\mathrm{N}$ \\
\hline 1. Forma como você foi chamado para trabalhar nesta agência & 6,34 & 94,5 & 91 \\
\hline $\begin{array}{l}\text { 2. Testes que foram realizados para você ser escolhido para trabalhar } \\
\text { nesta agência }\end{array}$ & 5,12 & 59,3 & 91 \\
\hline 3. Qualidade do treinamento & 4,76 & 58,2 & 91 \\
\hline 4. Freqüência do treinamento & 4,32 & 49,5 & 91 \\
\hline 5. Aplicação dos conhecimentos adquiridos através do treinamento & 5,05 & 68,1 & 91 \\
\hline 6. Oportunidade de participar de Famtours & 3,29 & 31,9 & 91 \\
\hline 7. Forma como seu desempenho no trabalho é avaliado & 4,89 & 63,7 & 91 \\
\hline 8. Remuneração recebida em relação às atividades executadas & 4,48 & 58,2 & 91 \\
\hline 9. Remuneração recebida em relação à que outras agências oferecem & 4,87 & 62,6 & 91 \\
\hline $\begin{array}{l}\text { 10. Beneficios (vale refeição, transporte e etc.) recebidos em relação aos } \\
\text { que outras agências oferecem. }\end{array}$ & 4,73 & 61,5 & 91 \\
\hline 11. Comissão do emissor em relação à que outras agências repassam & 4,64 & 58,2 & 91 \\
\hline $\begin{array}{l}\text { 12. Oportunidade de crescimento para outros cargos mais elevados, que } \\
\text { envolvam maiores responsabilidades. }\end{array}$ & 4,21 & 38,5 & 91 \\
\hline $\begin{array}{l}\text { 13. Transparência das informações (comunicaçôes são claras dentro da } \\
\text { agência; todos sabem o que acontece) }\end{array}$ & 4,76 & 61,5 & 91 \\
\hline 14. Oportunidade de expressar a sua opinião sobre os assuntos da agência & 5,11 & 67,0 & 91 \\
\hline 15. Ambiente físico da agência (condições de trabalho em termos de & 6,07 & 87,9 & 91 \\
\hline
\end{tabular}

\begin{tabular}{lcccc}
\hline \multicolumn{1}{c}{ Itens } & \multicolumn{3}{c}{ \% Concorda } \\
& Média & (b) & N \\
& (a) & & \\
\hline 16. Equipamentos disponiveis para a execução do trabalho & 6,26 & 93,4 & 91 \\
17. Relacionamento com os colegas & 6,47 & 93,4 & 91 \\
18. Relacionamento com as chefias & 6,02 & 87,9 & 91 \\
19. Reconhecimento do trabalho através de incentivos não-financeiros & 3,58 & 34,1 & 91 \\
$\quad$ (eleição de funcionário do mês e outros) & & & \\
20. Liberdade para tomar decisões em relação ao trabalho exercido & 4,88 & 64,8 & 91 \\
21. Satisfação com o trabalho exercido & 5,91 & 85,7 & 91 \\
22. Contribuição do seu trabalho para o sucesso da agência & 6,12 & 93,4 & 91 \\
\hline
\end{tabular}

(a) 1 = "insatisfeito" a $7=$ "muito satisfeito"

(b) $\%$ concorda $=5$ (satisfeito) a 7 (muito satisfeito) na escala de 7 pontos.

"N" = número total de questionários aplicados.

Fonte: Análise do banco de dos (2005).

Estes dados estão em consonância com a teoria, pois mostram, por exemplo, que o item salário não é o único responsável pela satisfação dos funcionários em uma empresa, ficando nesta amostra com a média de 4,48 e com concordância de $58,2 \%$. Este fato pode também indicar a baixa satisfação em relação ao Famtour, que em turismo é um incentivo não-financeiro, um tipo de premiação que os emissores recebem e que mostrou a menor média nesta pesquisa 3,29 e um grau de concordância de apenas 31,9\%. Estes dados encontram suporte nas afirmaçōes de Bohlander et al. (2003) que dizem ser o sistema de recompensa um fator de reconhecimento e subsistência para os funcionários, sendo composto de todas as formas de pagamento (financeiros e não-financeiros).

Da mesma forma é possível verificar que os funcionários desta amostra agregam valor a fatores como um bom relacionamento entre colegas além de se satisfazer ao imaginar que o seu trabalho pode contribuir para o crescimento e sucesso da empresa em que trabalha. Portanto, pode-se dizer que a satisfação com o trabalho é um somatório de diferentes elementos financeiros e não financeiros (Robbins, 2002).

\section{Análise fatorial da escala satisfação com as práticas e políticas de RH}

A primeira rotação da análise fatorial gerou seis fatores, com cargas fatoriais insatisfatórias em alguns itens. Os itens 6, 12, 13, 19 e 22 do questionário foram extraídos por apresentarem cargas abaixo do aceitável e no caso do item 19 ("Reconhecimento do trabalho através de incentivos não financeiros"), por causa de 
duplicidade. Desta forma optou-se por rodar uma nova análise fatorial, do tipo confirmatória, já solicitando a extração dos cinco itens citados, que resultou nos dados apresentados no Quadro 1.

Quadro 1. Satisfação com as práticas e políticas de RH

\begin{tabular}{|c|c|c|c|c|c|c|c|c|}
\hline & Itens & F1 & F2 & F3 & F4 & F5 & F6 & Alfa \\
\hline \multirow[t]{5}{*}{1} & $\begin{array}{l}\text { Remuneração recebida em relação às } \\
\text { atividades executadas }\end{array}$ & 0,859 & & & & & & \multirow[t]{5}{*}{0,88} \\
\hline & $\begin{array}{l}\text { Remuneração recebida em relação à que } \\
\text { outras agências oferecem }\end{array}$ & 0,853 & & & & & & \\
\hline & $\begin{array}{l}\text { Comissão do emissor em relação à que outras } \\
\text { agências repassam }\end{array}$ & 0,835 & & & & & & \\
\hline & $\begin{array}{l}\text { Benefícios (vale refeição, transporte e etc.) } \\
\text { recebidos em relação aos que outras agências } \\
\text { oferecem }\end{array}$ & 0,790 & & & & & & \\
\hline & $\begin{array}{l}\text { Forma como seu desempenho no trabalho é } \\
\text { avaliado }\end{array}$ & 0,510 & & & & & & \\
\hline \multirow[t]{4}{*}{2} & Qualidade do treinamento & & 0,899 & & & & & \multirow[t]{4}{*}{0,90} \\
\hline & Freqüência do treinamento & & 0,857 & & & & & \\
\hline & $\begin{array}{l}\text { Aplicacão dos conhecimentos adquiridos } \\
\text { através do treinamento }\end{array}$ & & 0,799 & & & & & \\
\hline & $\begin{array}{l}\text { Testes que foram realizados para você ser } \\
\text { escolhido para trabalhar nesta agência }\end{array}$ & & 0,773 & & & & & \\
\hline \multirow[t]{4}{*}{3} & Satisfação com o trabalho exercido & & & 0,833 & & & & \multirow[t]{4}{*}{0,81} \\
\hline & Relacionamento com as chefias & & & 0,736 & & & & \\
\hline & $\begin{array}{l}\text { Oportunidade de expressar a sua opinião sobre } \\
\text { assuntos da agência }\end{array}$ & & & 0,715 & & & & \\
\hline & $\begin{array}{l}\text { Liberdade para tomar decisões em relação ao } \\
\text { trabalho exercido }\end{array}$ & & & 0,647 & & & & \\
\hline \multirow[t]{2}{*}{4} & $\begin{array}{l}\text { O ambiente físico da agência (condições de } \\
\text { trabalho em termos de instalaçōes }\end{array}$ & & & & 0,896 & & & \multirow[t]{2}{*}{0,76} \\
\hline & $\begin{array}{l}\text { Equipamentos disponíveis para a execução do } \\
\text { trabalho }\end{array}$ & & & & 0,883 & & & \\
\hline 5 & Relacionamento com os colegas & & & & & 0,705 & & \\
\hline 6 & $\begin{array}{l}\text { Forma como você foi chamado para trabalhar } \\
\text { nesta agência }\end{array}$ & & & & & & 0,896 & \\
\hline
\end{tabular}

Método de extração: Principal Component Analysis.

Método de Rotação: Viramax with Kaiser Normalization

Fonte: Análises multivariadas aplicadas ao banco de dados (2005)
O primeiro fator gerado refere-se à dimensão aqui denominada sistema de remuneração e foi composto por cinco itens. O aparecimento desta dimensão, como sendo a principal na explicação da satisfação dos funcionários, demonstra o quanto as pessoais ainda são motivadas por incentivos financeiros. Entretanto, o segundo fator que representa a dimensão aqui denominada de treinamento, agrupou quatro itens referentes ao treinamento dentro da empresa. Esta segunda dimensão também teve grande relevância na satisfação dos funcionários, ratificando que não apenas os incentivos financeiros satisfazem, mas a preocupação em crescer dentro de sua função por meio de oportunidades de treinamentos, também influencia a satisfação de um funcionário dentro da empresa. Estes dois fatores juntos explicam $48,78 \%$ dos itens que satisfazem os funcionários em relação às práticas e políticas de recursos humanos praticadas pelas agências de viagens que fizeram parte do estudo.

O terceiro fator é composto por 4 itens e representa a dimensão aqui denominada de chefia e autonomia. Esta dimensão compreende questões relativas ao relacionamento com a chefia, liberdade de expressão e decisão e satisfação com o trabalho. Sendo a satisfação com o trabalho o item que obteve maior carga $(0,833)$ nesta dimensão. $\mathrm{O}$ quarto fator foi gerado por 2 itens e representa a dimensão aqui denominada de tangibilidade. Nota-se então que os funcionários também não percebem os fatores tangíveis da empresa como responsáveis pela sua satisfação, mas como um pré-requisito para que os mesmos possam efetuar seu trabalho. $\mathrm{O}$ quinto e o sexto fator foi gerado apenas com um único item, apresentando carga fatorial de 0,705 e de 0,896 respectivamente.

\section{Considerações finais}

Tendo como objetivo identificar a importância das políticas e práticas de RH na satisfação dos funcionários das agências de viagens, o presente estudo foi realizado no ambiente interno de oito agências localizadas na Região Metropolitana do Recife.

O objetivo específico proposto foi mensurar o nível de satisfação dos funcionários de linha de frente das agências de viagem em relação ao seu trabalho. $\mathrm{O}$ resultado encontrado mostra que $85,7 \%$ dos funcionários afirmam estar satisfeitos com o seu trabalho. Este fato pode ser reflexo da utilização de pesquisas de satisfação dos funcionários praticadas pelas agências de viagens. Estas pesquisas internas são poderosas ferramentas que podem indicar práticas e políticas que precisam ser aplicadas e/ou mudadas na empresa, visando o bem-estar do funcionário. 
O Quadro 2 mostra os fatores que mais contribuem para a satisfação dos funcionários.

Quadro 2. Satisfação com as práticas e políticas de RH

\begin{tabular}{|l|c|c|c|}
\hline \multicolumn{1}{|c|}{ Dimensões (ou Fatores) } & $\begin{array}{c}\text { Confiabilidade } \\
\text { (Alfa) }\end{array}$ & Itens & Variância acumulada (\%) \\
\hline treinamento & 0,90 & 4 itens & \multirow{2}{*}{48,78} \\
\hline sistema de remuneração & 0,88 & 5 itens & \\
\hline chefia e autonomia & 0,81 & 4 itens & \\
\hline tangibilidade & 0,76 & 2 itens & \\
\hline relacionamento & - & 1 item & \\
\hline seleção & - & 1 item & \\
\hline
\end{tabular}

Fonte: Dados da pesquisa, 2005

Foi observado, através da análise fatorial, que os itensreferentes ao treinamento e à remuneração, foram os que mais explicaram a satisfação dos funcionários desta amostra. Estes dois fatores juntos explicaram $48,7 \%$ da escala de satisfação com práticas e políticas de recursos humanos.

O terceiro fator da escala agrupou 4 itens referentes à comunicação, autonomia e satisfação com o trabalho. O quarto fator agrupou dois itens referentes aos aspectos tangíveis. O quinto e o sexto fator agruparam um único item cada, referente à comunicação e à seleção, respectivamente.

De acordo com estes dados, a recompensa aparece como um meio poderoso de satisfação de funcionários. Estas recompensas podem ser extrínsecas (salário), ou intrínsecas, como gostar do próprio trabalho, crescer profissionalmente através de treinamentos ou ser reconhecido por colegas e superiores.

Os resultados encontrados nesta pesquisa estão em concordância com Gubman (1999), que afirma que os funcionários buscam em seus empregos uma possibilidade de aprendizagem, além de tratamento justo e bom relacionamento com colegas e outras pessoas. Fatores estes que podem ser desenvolvidos através de uma boa gestão das práticas e políticas de recursos humanos.

\section{Referências bibliográficas}

ABAV - Associaçāo Brasileira de Agências de Viagens. 2004. Disponível em: <http://www.abav-pe.com. br> . Acesso em: 25 dez. 2004.

ALBRECHT, Karl. 1993. A única coisa que importa: trazendo o poder do cliente para o centro de sua empresa. São Paulo: Pioneira.
ALBUQUERQUE, Lindolfo G. 1999. Estratégias de recursos humanos e competitividade. In: VIEIRA, Marcelo M. F. \& BARBOSA, Lúcia M. de O. (Orgs.). Administraçāo contemporânea: perspectivas estratégicas. São Paulo: Atlas.

ANDRADE, José V. 1998. Turismo: fundamentos e dimensōes. São Paulo: Ática.

ARNET, Dennis B., LAVERIE, Debra A. \& McLANE, Charlie. 2002. Using job satisfaction and pride as internal-marketing tools. Cornell Hotel and Restaurant Administration Quarterly, Ithaca, Apr. 2002.

BASTOS, A. V. B. 1994. Comprometimento organizacional: um balanço dos resultados e desafios que cercam essa tradição de pesquisas. Revista de Administraçāo de Empresas, São Paulo, v. 33, n. 3, p. 52-64.

BENI, Mário Carlos. 1996. Comunicaçāo e concorrência no mercado internacional. Turismo em Análise. São Paulo: ECA-USP, v. 7, n. 1, maio.

BOHLANDER, George W., SNELL, Scott \& SHERMAN, Arthur. 2003. Administraçāo de recursos humanos. São Paulo: Pioneira Thomson Learning.

BROWN, Steven P. \& PETERSON, Robert A. 1993. Antecedents and consequences of salesperson job satisfaction: meta-analysis and assessment of causal effects. Journal of Marketing Research, v. 10, n. 1, p. 63-77, Feb.

CURADO, Isabela B., PEREIRA FILHO, João Lins \& WOOD JR., Thomaz. 1995. A gestāo de recursos humanos na grande São Paulo. São Paulo: SENAC-SP. (Série Linha de Pesquisa).

DENTON, D. K. 1990. Qualidade em serviços: o atendimento ao cliente como vantagem competitiva. São Paulo: Makron Books.

DONOSO, Gabriela. 2000. Marketing interno: desafío para las empresas de servicios turísticos. Estudios y Perspectivas en Turismo. v. 9, p. 112-130.

EMBRATUR - Instituto Brasileiro de Turismo. 2001. Anuário Estatístico 2001. Ministério do Esporte e Turismo. Brasília-DF.

2003. Anuário Estatístico 2003. Ministério do Esporte e Turismo. Brasília-DF.

GIACOMINI FILHO, Gino. 1997. Empresa turística voltada ao atendimento. Turismo em Análise. São Paulo: ECA-USP, v. 8, n. 2, p. 44-58, nov.

GIANESI, Irineu G. N. \& CORRÊA, Henrique L. 1996. Administraçāo estratégica de serviços. São Paulo: Atlas.

GIL, Antônio C. 1999. Métodos e técnicas de pesquisa social. 5. ed. São Paulo: Atlas.

GUBMAN, Edward. 1999. Talento: desenvolvendo pessoas e estratégias para obter resultados extraordinários. Rio de Janeiro: Campus.

GUEIROS, Manuela G. \& OLIVEIRA, Lúcia M. B. 2002. Qualidade de vida no trabalho: um estudo no setor de hotelaria na regiāo metropolitana do Recife. ENCONTRO NACIONAL DAASSOCIAÇĀO NACIONAL DE POSGRADUAÇĀO EM ADMINISTRAÇĀO - ANPAD, 26. Anais da área temática de RH, Salvador, 2002. CD-ROM.

2004. Clientes internos satisfeitos com as práticas de RH conduzem à satisfação dos clientes externos? Um estudo no setor hoteleiro. ENCONTRO NACIONAL DA ASSOCIAÇĀO NACIONAL DE POS-GRADUAÇĀO EM ADMINISTRAÇĀO - ENANPAD, 28. Anais da área temática de RH, Salvador, 2002. CD-ROM.

HIPÓLITO, José A. M. \& REIS, G. G. 2002. Sistemas de recompensas: uma abordagem atual. In: FLEURY, Maria Tereza L. (Coord.). As pessoas na organizaçāo. São Paulo: Gente.

KOTLER, P., BOWEN, J. \& MAKENS, J. 1999. Marketing hospitality and tourism. 2. ed. NJ-USA: PrenticeHall.

LAS CASAS, A. L. 1997. Qualidade total em serviços: conceitos, exercícios e casos práticos. São Paulo: Atlas.

LIMONGI-FRANÇA, Ana Cristina \& ARELLANO, Eliete B. 2002. Os processos de recrutamento e seleçāo. In: FLEURY, Maria Tereza L. (Coord.). As pessoas na organizaçāo. São Paulo: Gente. 
LOCKE, Edwin A. 1969. What is job satisfaction? Organizational Behavior and Human Performance, v. 1, n. 3, p. 309-336.

MÖLLER, C. 1999. O lado humano da qualidade: maximizando a qualidade de produtos e serviços através do desenvolvimento das pessoas. 12. ed. São Paulo: Pioneira.

PORTER, Michel. 1994. Seminário Reinventando a estratégia. HSM, São Paulo, 6 dez.

ROBBINS, Stephen P. 2002. Comportamento organizacional. 9. ed. São Paulo: Prentice Hall.

RUSCHMANN, Doris. 1992. Marketing turistico: um enfoque promocional. Campinas-SP: Papirus. (Coleção Turismo).

SCHNEIDER, Benjamin. 1980. The service organization: climate is crucial. Organizational Dynamics, 9, (Autumm), p. 52-69.

SWARBROOKE, John. 2000. Turismo sustentável: gestão e marketing. São Paulo: Aleph.

TOMELIN, Carlos Alberto. 2001. Mercado de agências de viagens e turismo: como competir diante das novas tecnologias. São Paulo: Aleph.

TSCHOHL, John. 1996. A satisfação do cliente: como alcançar a excelência através do serviço ao cliente. São Paulo: Makron Books.

ULRICH, Dave (Org.). 2000. Recursos humanos estratégicos: novas perspectivas para os profissionais de recursos humanos. São Paulo: Futura.

VERGARA, Sylvia C. 1998. Projetos e relatórios de pesquisa em administrwação. São Paulo: Atlas.

Recebido em: 29/05/2006.

Aprovado em: 14/05/2007. 